\title{
Impact of Information Accessed Through Social Capital on Rational Ability of Owner Manager Small Enterprises in Sri Lanka
}

\author{
H. M. S. Priyanath ${ }^{1, ~ *, ~ S . ~ P . ~ P r e m a r a t n e ~}{ }^{2}$ \\ ${ }^{1}$ Department of Economics and Statistics, Sabaragamuwa University of Sri Lanka, Belihuloya, Sri Lanka \\ ${ }^{2}$ Department of Economics, University of Colombo, Colombo, Sri Lanka
}

Email address:

priya@ssl.sab.ac.lk (H. M. S. Priyanath)

${ }^{*}$ Corresponding author

\section{To cite this article:}

H. M. S. Priyanath, S. P. Premaratne. Impact of Information Accessed through Social Capital on Rational Ability of Owner Manager Small Enterprises in Sri Lanka. European Business \& Management. Vol. 3, No. 4, 2017 pp. 65-75. doi: 10.11648/j.ebm.20170304.12

Received: June 26, 2017; Accepted: July 11, 2017; Published: October 23, 2017

\begin{abstract}
The study explored how information accessed through Social Capital (SC) affect the improvement of rational ability of Owner Manager Small Enterprises (OMSEs) in Sri Lanka. Data were collected from 373 Small Enterprises (SEs) located all the Provinces in Sri Lanka, conducting face to face interviews with respondents. The data were analysed using Partial Least Squares-Structural Equation Modelling. The results provided sufficient evidences to conclude that information access through different dimensions of SC (structural, relational and cognitive) have significant positive effects on the improvement of rational ability of OMSEs in Sri Lanka. The empirical results expand the understanding the relative efficacy of SC and rational ability in the context of SEs in a less develop country and deliver an alternative insights for policy makers to develop SEs by creating a conducive environment for strengthening SC of SEs in order to access more information.
\end{abstract}

Keywords: Information Asymmetric, Owner Manager Small Enterprises, Rational Ability, Social Capital, Transaction Costs

\section{Introduction}

The decision making ability particularly owners (entrepreneurs) of SEs is more bounded due to the lack of information, lack of resources to access information and lack of knowledge and experiences to evaluate information [1], [2], [3]. Entrepreneurs have no sufficient resources to search information and to obtain support from experts to make rational decisions [4]. Therefore, the rational ability of the owner of SEs is relatively more bounded [4] and as a result, SEs suffer hazards from opportunism which leads to increase Transaction Cost (TC). Scholars [4], [5] emphasized that SEs have higher TC compared to large firms because entrepreneurs suffer hazards from opportunism of exchange partners due to asymmetrical information. Entrepreneurs do not have capacity to collect and evaluate information due to various barriers including geographical barriers in remote areas with poor infrastructure facilities, lack of knowledge to access and assess information, lack of time and capacity to gather and handle information, lack of resources to access and evaluate information, lack of knowledge and experiences [2], [3], [4], [5]. Further, SEs do not have sufficient resources to recruit specialists to make good decisions searching and evaluating information [4], [5]. eforeTher, the TC of SEs are very high [4] .

Some studies [6], [7], [8] underlined that SEs use informal and personal connections in order to access information. These informal and personal connections do not have formal and written agreement but these connections are based on network relationships with family members, relatives, friends, supportive institutions and the others (6], [7]. Literature describes that the network relationship leads to generate Social Capital (SC) [6], [9], [10]. Key benefit of SC is that it facilitates to reach information reducing information asymmetric which allows to improve rational ability [11], [12], [13]. Therefore, the current study attempted to explore how information accessed through SC affects the improvement of rationality of OMSEs? In the literature, dearth of empirical evidence regarding the effect of 
information accessed through SC on rational ability particularly in SEs represents a major gap. The current study attempts to bridge this gaps. Therefore, main objective of this paper is to explore how information accessed through SC affects the TC particularly OMSEs in Sri Lanka. The empirical findings of this study will definitely contribute the policy makers to develop alternative policies to achieve fast growth of SEs on the one hand and will facilitate SEs to achieve their business success on the other hand.

\section{Theoretical Background}

Social Capital Theory: SC implies the value and resources that generated from social relationships. Coleman [14] claimed that unlike other types of capital, SC is the structure of relations between actors and among actors. Coleman [14] highlighted three characteristics of SC: a) expectations and trustworthiness, b) information channels and c) norms. Each feature provides resource for individuals. According to Putnam [15], key features of SC are; a) moral obligations and norms, b) social values (especially trust) and c) social networks (especially voluntary associations) all facilitate coordination and cooperation for the mutual benefit. SC consists of features of relationship among individuals such as networks, high levels of interpersonal trust and norms of mutual supports which act as resources for individuals and facilitate for collective action [11], [15], [16], [17]. SC has three dimensions; structural, relational and cognitive [18].

Structural Social Capital (SSC) is referred as resources that generate due the pattern of relationships among individuals. Important aspects of the SSC are the pattern of ties between the members of a social network; network structure based on density of ties and frequency of connectivity and interaction [18]. Thus, scholars [6], [19], [20] highlighted that network size (total number of actors that the focal firm is connected to) and the density of network (existing connections out of potential connections) are as the two reflective attributors of SSC.

The Relational Social Capital (RSC) refers as resources that generate from the value of relationships among individuals. The RSC has two broad attributors: a) strength of relationships and b) quality of relationships which are reflected by inter-personal trust (the willingness to be vulnerable to another person) [21], norms (generalized expectations of behavior, such as norms of reciprocity, flexibility, solidarity, reciprocity and role of integrity) [22], [23], [24], [25].

Cognitive Social Capital (CSC) refers to the resources that provide shared vision or common understand among network members [18]. In business perspective, CSC implies the value of common understanding among exchange partners [26]. This aspect of social capital consists of the value such as common vision that supports a common understanding of shared goals, norms of action and social trust in a social setting [27]. The way that the network members show their norms, trust and commitment in reality is the CSC [28] Shared vision is the key element of CSC. A shared vision occurs among network members, they will be easier to interact with each other since they have similar perceptions [28].

Bounded Rationality: Transactions between exchange partners are coordinated by demand and supply through price mechanism in a perfectly competitive market [29]. If exchange partners have perfect knowledge about the market (prices, quality etc.), transaction will take place in a reasonable manner for both partners. However, perfect competitive market is far away from the reality and exchange partners need to bear costs when using imperfect market mechanism [10]. TC generates due to imperfect market mechanism [30]. According to Hobbs [1], many business exchanges are based on incomplete, imperfect or asymmetrical information. Information incompleteness refers to the situation where all parties to a transaction face incomplete levels of information [31]. Asymmetrical information averts business firm to make rational decisions which is called as bounded rationality [31]. Therefore, transactions tend to become costly. The costs incurred by a firm when using market mechanism to search information the lowest price to purchase and the highest price to sale, negotiate with exchange partners to reach transaction agreements and monitor transaction process is called as TC [31].

Although people may intend to take a rational decision, their capacity to collect information and evaluate them to make the best decision is physically limited. Bounded rationality describes the limited extent to which people make rational decisions. Bounded rationality refers that the imitations in collecting, processing and assessing information in order to make rational decision [32]. Making a full rational decision requires unlimited intellectual capabilities. Literature highlighted three types of mental bounds i.e. limitation of collecting information due to asymmetrical information (all parties to the transaction no longer possess the same levels of information because imperfect market mechanism generates imperfect information), limitation of processing information due to the lack of knowledge and mental capacity (human mind has only limited capacity to evaluate and process the information) and the limitation to make full rational decision (full rationality requires unlimited mental capabilities) [32]. Therefore, decision makers have limited cognitive capacity in solving complex problem. Thus, bounded rationality explains the limited ability of humans to access, assess and process information [31], [33]. If bounded rationality does not exist, transaction between partners could be efficiently organized [1]. Transaction between partners could not be efficiently organized due to bounded rationality [34]. Business firms need to careful to make decisions if sufficient information will not be existed. Firms incur costs to search adequate information, assess information, and get legal advices etc. before making important transaction decisions [8]. It means that bounded rationality increases TC showing a positive relationship between bounded rationality and TC [1]. 


\section{Research Model and Hypotheses}

The conceptual research model is developed synthesizing both Social Capital Theory (SCT) and the Bounded Rational Theory (BRT). Three dimensions of SC represent the independent variables while rational ability signifies the dependent variable.

SSC and Rational Ability: Asymmetrical information existing in imperfect market mechanism limits the rational ability of a person/firm [12], [13]. If a buyer can access to more information, exchange partners cannot behave opportunistically [35]. The buyer has an ability to make more rational decision avoiding opportunism.

There are two theoretical arguments offered by scholars in regarding how network structure affect the gain access to information i.e. Coleman's [14] network closure argument and Burt's [16] structural hole argument. Coleman [14] explained that dense network creates situations where quick information are exchanged among members. The structure of a network refers to the relative density of links among people within it that facilitates the flow of information and the provision of social support to the social structure in which a person or a tie is embedded [36]. Bouzdine and Lorgnier [37] explained that members in a dense network are closely connected via communication. Dense networks are also likely to provide 'fine-tuned' information, which can quickly be transformed into successful opportunities [38]. Burt [16] argued that sparse network is more beneficial than dense. In sparse networks, the chances of having contacts who do not know one another increase. Such contacts are likely to be sources of new information that potentially generates benefits for the business firm [16]. However, Bouzdine and Lorgnier [37] highlighted that both structural holes and dense can be brought together in a productive way to share information and new knowledge.

SEs are unable to achieve goals by themselves alone [10]. To do so, SEs expect information, supports, resources and ideas from networks [39]. SEs usually get support from network members to gather information, evaluate information, and get ideas and advice before making crucial transaction decision [40]. Close members of the network provide opportunities for interpersonal contact and leads to more positive feelings about providing supports, sharing information and resources with those with whom they develop a close relationship [26]. Members of the network who have strong network relationship would perceive greater social pressure for supporting and sharing their knowledge and information, because a good relationship results in high expectations of colleagues, including favorable actions [26]. Thus, network structure has the ability to access information and get the support to evaluate information. As a result, rational ability of the OMSE becomes improve due to the information access through network structure and support obtained from members of the network to evaluate such information. Nooteboom [4] explained that increasing the ability to spread of personal networks (size), rationality could be improved. SEs can obtain specialist' ideas, opinions and experiences from supportive networks with low costs and rational ability of SEs can be improved extending their network. Thus, information access through the SSC (network size and network dense) helps SEs to mitigate information asymmetric facilitating to access and evaluate information which leads to improve rational ability of OMSEs. Therefore, study hypothesizes that;

H1 Network size of the OMSEs relates positively to the rational ability of the owner of small enterprise.

H2 Network density of the OMSEs relates positively to the rational ability of the owner of small enterprise.

Strength of Relationships and Rational Ability: Ahmad and Seet [41] highlighted that non-rational behavior of the SEs in managing the business, contributes to business failure. Lack of knowledge about the business environment, lack of information, lack of business experience and poor decision making ability were identified as the causes of business failure. Network theory explained that inter-personal relationships developing strong ties, bonding and bridging affect the access to reliable information and knowledge which facilitates SEs to improve rational ability [20].

Nooteboom [4] explained that rational ability of SEs is more bounded due to lack of knowledge, information, resources and experiences. SEs expect reliable information, knowledge and moral supports from relational ties (strong ties, bonding and bridging ties) and expect support to assess information in order to make rational decision [42]. In SCT, there are two arguments on whether strong or weak ties provide more benefits. Strong ties provide information that the other parties are already aware of. Weak ties are likely to provide new information because they are likely to be moving in distant social circles [16], [43]. In addition, networks where the members do not or hardly know each other provide new information. Burt [16] refers to these networks as having many holes in the social structure. Such networks offer bridging opportunities that enable to go beyond his immediate network. Granovetter [43] proposed that weak rather than strong ties are appropriate for access to new information. This helps firms to reduce searching for alternative sources of information or exchange partners, which in turn result in greater economic advantages [38].

Weak ties can be viewed as a bridge between clusters of strong relationships, and could bring in new information from distant circles [9], [43]. Weak ties provide the bridges over the boundaries of social groups whereas the influence on the decision making is done mainly by the strong ties network within each group [44]. Information flows freely from one group to another group and the bridging tie remains open to allow the flow of information [45]. Strong ties promote the development of trust, the transfer of information and tacit knowledge, and joint problem-solving [38, 46]. In Putnam's [15] view, bonding SC reflects strong ties with family and close friends, who might be in a position to provide emotional support to access to rare information [47]. Bridging ties facilitate the exchange of information between distinct groups, and help to expedite the flow of ideas among groups [44].

These theoretical implications provide a base to the 
importance of developing the strength of relationship. Khalique et al. [48] explained that failure to establish strong contacts was a major reason for business failure. If SEs are rich in RSC they will have ability to access information, knowledge and obtain advice and opinion which leads to improve rational ability [26]. Therefore, the study predicts that;

H3 Strength of the relationships of the OMSEs positively relates to the rational ability of the owner of small enterprise.

Quality of the Relationship and Rational Ability: Relational ties lead to develop trust with one another [20]. Along with the relational ties, trust and norms are important sources of the RSC [11]. Inter-personal trust among the members of network contributes to the free exchange of information between exchange partners, because decision makers do not feel that they have to protect themselves from others' opportunistic behavior [39]. Inter-personal trust plays a key role in the willingness of network actors to share information [39]. Members of network share information about the trustworthiness of other members. The trustworthiness of the members of network makes them more confident in information exchange [27]. Chow and Chan [26] explain that mutual trust among network members is one of critical factors to the success of information sharing. Mutual trust improves interactions among the members of network facilitating to learn from each other and share their knowledge [26]. The level of mutual trust influences expectations of a colleague's intention and behavior. Network members are thus more likely to expect those who are trustworthy to support and share their knowledge [26]. Thus, RSC (inter-personal trust and relational norms among network members) helps SEs to access and assess information which leads to improve rational ability.

Relational norms also play an important role in exchanging information. Heide and John [49] explained that under the norm of information exchange parties provide useful as well as unforeseen information to each other, which would ease their functions and enable them to fulfill their role more efficiently. Anderson and Weitz [50] described that the exchange of useful information that helps parties to coordinate their activities better ultimately resulting in competent role performance. Scholars note that sharing information leads the channel partners to believe that the relationship would continue, as a result of which partners become more tolerant towards each other's mistakes. Exchange parties become more satisfied with each other when partners share information. According to Doucette [51], information sharing enables channel partners to coordinate activities better as well as to be more competent in performing roles. Moreover, Doucette [51] remarked that as result of this norm, exchange partners trust each other.

The norm of information exchange helps share useful information [49], [51] and confidential information [23]. If the members of network think a particular piece of information is useful to the other party, partner would provide it. Information regarding market prices, unforeseen market trends and threats are regularly share among strong ties [49]. Confidential information only disclosed to trusted partners, usually not revealed to common exchange partners with whom one time transactions are performed. To reveal this type of information, it requires a high level of trust between exchange parties. For example, for a supplier to inform his buyer information regarding production costs, product design or innovations, the buyer should trust the partner not to take undue advantage of that information such as squeezing the profit margins or revealing that information to competitors [38]. Thus, quality of relationship affects the improvement of rationality and therefore the following hypothesis is developed.

H4 Quality of the relationship between the OMSEs and the members of the network positively relates to the rational ability of the owner of small enterprise.

The CSC and Rational Ability: Common understanding amongst network members leads to sharing of resources and interactions among network members that lead to the sharing of common goals throughout the network [27]. Network members do not fear pursuit of self-interest by any other member of the network if they have common understanding. Hence, common understanding is a binding force that creates trust and lead to information sharing [27]. Chiu et al. [52] in their empirical study found that common understanding was positively related to the quality of information and knowledge sharing. The shared goals promote mutual understanding and exchange of ideas and opinions. Thus, common understanding is considered as the force that holds people together and to share knowledge and information. Within network, common understanding is achieved through cooperation and knowledge sharing [26]. With collective goals, network members tend to believe that other's self-interest will not affect adversely and network members all contribute their knowledge to help achieve their mutual success [26]. Thus, cognitive social capital helps SEs to access and assess information which facilitates to improve rationality (mitigate bounded rationality). Therefore, the study assumes that;

H5 Shared vision between the OMSEs and the members of the network positively relates to the rational ability of the owner of small enterprise.

\section{Methodology}

The research paradigm of this study was based on the deductive approach because both SCT and BRT provide strong foundation to develop dependent and independent variables. Quantitative approach is employed to study the research problem and the survey method was selected to gather data. Only owner manage manufacturing SEs, which are classified according to 2 digit levels of ISIC-Revision, 4 (UNDP) were selected to gather data. Department of Census and Statistics (DCS) in Sri Lanka defines SEs as 'establishment with 5 - 24 persons engaged' and the same definition was used to select SEs for the survey. According to the DCS, there were 71,126 SEs dispersed in Sri Lanka and the study employed those SEs as the study population.

Multi-stage sampling method was adopted to determine the sample. First, the study selected only the enterprises 
classified under manufacturing category as the sample frame. According to the Economic Census in 2013/2014, there were 14,185 industries belonging to the category of manufacturing establishments.

Second, using the sample frame (14,185 of SEs), 376 of SEs were selected employing the sample size determination formula developed by Krejcie and Morgan [53] with 95 percent confidence level and 5 percent margin of error.

Third, the sample is distributed according to the percentage share of the SEs located in each district and determine the number of firms to represent all the district in Sri Lanka. Then, SEs of each districts were listed out according to International Slandered of Industrial Classification (ISIC) and the sample were selected using stratified sampling method to represent all the manufacturing industrial divisions.

The study used two step procedure to develop questionnaire. Initially a pool of items of each dimensions was generated reviewing empirical literature and items were carefully selected. Items are more relevant to measure the particular dimension of the constructs. Thus, the questionnaire items were designed systematically based on literature published in cited journals. Then, a pilot survey was conducted prior to the main questionnaire survey in order to verify whether the questions are understood; whether instructions are clear; whether the order of the questions is appropriate and the questions are uninspiring etc. This helped to increase the validity and the reliability of the study. Data were collected for the questionnaire conducting face to face interviews. The unit of analysis is each owner of SEs because the owner is the 'entrepreneur' in many SEs who starts and manages the business.

Partial Least Square - Structural Equation Modeling (PLSSEM) was used to test the hypothetical relationships because it helps to examine the interrelationship between multiple independent and dependent variables and facilitates the evaluation of relationships between more than one construct simultaneously. Measurement model is evaluated employing reliability and validity tests and the efficiency of the structural model was evaluated by multi-collinearity issues, $\mathrm{R}^{2}$, effect size $\left(\mathrm{f}^{2}\right)$ and predictive relevance $\left(\mathrm{Q}^{2}\right)$. The smartPLS (version2) software was used to analyze data.

\section{Measures}

All the constructs were measured using structural questions. Each items were measured at an ordinal level with 7-point Likert scales (1 - Strongly disagree; 2 - Disagree; 3 Somewhat disagree; 4 - Neither agree nor disagree; 5 Somewhat agree; 6 - Agree; 7 - Strongly agree). Each respondent was asked to state their agreement to the statements using these rankings.

SSC: The study assessed SSC using network size and network density. The network size of the OMSEs is simply defined as the number of persons that SEs is directly connected to. This measurement was adopted by Bhagavatula [6]; Moran [17]; Premaratne [10]. The network density of the OMSEs is simply defined as the total number of persons that the OMSE deals business activities with and obtains support such as information, resources and moral support. The network density is measured as the percentage of close relationships within the total number of possible relationships of the OMSE. This is adopted by Bhagavatula [6]; Burt [16]; Premaratne [10].

RSC: The study considers the RSC as assets embedded with strength and quality of relationships. It refers to the kinds of relationships that the actor has developed with each other through a history of interactions [54], [55]. Considering the SEs, the RSC refers to the strength of relationships that SEs have developed with each other and quality of relationship including inter-personal trust and relational norms embedded with the relationships.

The strength of relationship is measured using Network Strength Index. It refers to what extent OMSEs maintains close ties with regular interaction in a long period. The study uses an index to measure the network strength. Lu et al. [56] adopted the same index. The study asked respondents to select the most important 12 members of different categories of network and provide answers to the following questions. How well do you know the person (very well, somehow, or very little)? How often do you contact this person (daily, weekly, or monthly)? How many years do you know this person? For the first two questions, a weight of 1, for answers of "very well" and "daily", 0.5, for "somehow" and "weekly", and 0.1, for "very little" and "monthly" are assigned. The network strength index was created by multiplying the three answers. The higher this value is, the stronger the ties are.

Ganesan [54] represented trust as a two-dimensional construct of credibility and benevolence (behavioral dimension). Inter-personal trust refers to the belief of entrepreneur that the network member is creditable (honest, flexible, fair and in no circumstance will purposely do anything to damage the relationship) and always shows the creditability by action (benevolence). Accordingly, creditability is evaluated employing three components i.e. reliability, predictability, and fairness and three items are used to measure benevolence all of which have been adopted by Ganesan [57]; Lu et al. [54]; Moran [17]; Zaheer et al. [58].

Study defines relational norms as the expectations about the behavior that are at least partially shared informal agreements between parties that have been shown to govern their relationships. Relational norms between OMSEs and network members are measured using five variables; information exchange, flexibility, solidarity, role of integrity and reciprocity. These variables have been adopted by Anderson and Weitz [50]; Doucette [51]; Dyer and Chu [23]; Heide and John [49]; Rokken et al. [46].

CSC: The CSC refers to the resources that provide a shared representation, an interpretation and systems of meaning. This dimension includes attributes common understanding, common perspectives and shared congruence, or generally agreed upon meanings [18]. CSC is embodied in attribute like a shared code or a shared paradigm that facilitates a common understanding of collective goals. A shared goal embodies the collective goals and aspirations among the network members [59].

Rational Ability: Bounded rationality has not been 
empirically measured by scholars. Instead, they measured opportunism since it is considered as the mirror of the bounded rationality of a person. As an alternative, the study attempts to measure the rational ability of the OMSEs (not bounded rational), using three dimensions; a) ability to access information which were measured using 8 items adopted by Ting et al. [35]. b) Ability to assess information which were measured using 4 items develop by the researcher employing the concepts of Williamson [21]; Zhang [32]; and c) Ability to make good transaction decisions is measured using 4 items develop by the researcher.

\section{Results and Discussion}

With regard to the personal characteristics of the sample, the majority ( 90.2 percent) of the OMSEs were males while female owners contribute 9.8 percent to the sample. Mean age of the owners is 51 years. The owners' age varies from minimum age of 27 to the maximum age of 71 . The majority of the owners ( 80.6 percent) belong to the age category between 40 years to 59 years, while only 5.4 percent fall into the under 39 years group, and 13.3 percent belong to the over 60 year group. In view of the academic background of the OMSEs, owners have a good formal educational background. Mean education of the owners is 3.6, which implies the average education of the owners varies between $\mathrm{O} / \mathrm{L}$ and A/L. Less than 40 percent of the owners have obtained below
G. C. E. Ordinary Level qualification while 6.5 percent of the owners have a degree. Nearly 60 per cent $(53.3$ percent: up to $\mathrm{A} / \mathrm{L}+6.5$ percent: Degree or above $=59.8$ percent) have academic qualifications beyond the G. C. E. Advance Level. In addition to formal education, business experience is more important in particular for the OMSEs. Mean business experience of the owners is 15 years. 27 percent of the owners have less than 10 year experience in the business field while 7.9 percent of the owners have more than 30 year experiences. 43.4 percent have business experience between 10 year and 19 year while 21.6 percent have business experience between 20 year and 29.

Based on PLS-SEM measurement of outer model, first, the study evaluated 13 of first order latent variables. The table 1 shows standardized factor loadings which were above than the minimum threshold criterion 0.7 confirming the indicator reliability of first order reflective constructs. In addition, the table 1 further shows that all the factor loadings were statistically significant at 0.05 significance level.

The Cronbach's $\alpha$ was higher than the required value of 0.7 and composite reliability was higher than the recommended 0.7 value. Higher value of the Cronbach's $\alpha$ and the composite reliability confirm the convergent validity of the first order constructs. Regarding the discriminant validity, none of the inter-construct correlation value was above the square-root of the AVE and satisfied the criterion of the discriminant validity of first order constructs.

Table 1. Analysis of the First Order Constructs.

\begin{tabular}{|c|c|c|c|c|c|c|}
\hline \multicolumn{2}{|c|}{ Construct } & \multirow[t]{2}{*}{ Loading } & \multirow[t]{2}{*}{$t$-statistics } & \multirow{2}{*}{$\begin{array}{l}\text { CR } \\
0.969\end{array}$} & \multirow{2}{*}{$\begin{array}{l}\text { AVE } \\
0.797\end{array}$} & \multirow{2}{*}{$\begin{array}{ll}\alpha \\
0.963\end{array}$} \\
\hline 1. & Ability to access information & & & & & \\
\hline & Ability to find accurate information about market prices for our product. & 0.859 & 41.38 & & & \\
\hline & Ability to find sufficient information about new markets and buyers & 0.928 & 80.40 & & & \\
\hline & Ability to find sufficient information about reliable buyers & 0.944 & 133.79 & & & \\
\hline & Ability to find sufficient information about threats coming from competitors & 0.929 & 99.94 & & & \\
\hline & Ability to find accurate information about input prices. & 0.867 & 80.40 & & & \\
\hline & Ability to find sufficient information about new input suppliers & 0.873 & 72.49 & & & \\
\hline & Ability to find sufficient information about reliable suppliers & 0.926 & 88.87 & & & \\
\hline & Ability to find sufficient information about product techniques & 0.810 & 46.12 & & & \\
\hline \multirow[t]{5}{*}{2.} & Ability to assess information & & & 0.917 & 0.735 & 0.879 \\
\hline & $\begin{array}{l}\text { Ability to evaluate information about the behavior of market prices of our products before } \\
\text { making important sale decision }\end{array}$ & 0.808 & 40.61 & & & \\
\hline & $\begin{array}{l}\text { Ability to evaluate the input prices and quality related to our products before making important } \\
\text { input purchase decision }\end{array}$ & 0.851 & 55.65 & & & \\
\hline & Ability to evaluate the potential threat coming from competitors & 0.910 & 110.14 & & & \\
\hline & $\begin{array}{l}\text { Ability to evaluate the change of business environment, political situations and external socks } \\
\text { (how such changes effect on my business). }\end{array}$ & 0.858 & 69.36 & & & \\
\hline \multirow[t]{5}{*}{3.} & Ability to Make Decision & & & 0.928 & 0.721 & 0.903 \\
\hline & Ability to make a satisfactory sale decision searching and evaluating information & 0.838 & 50.07 & & & \\
\hline & Ability to make a satisfactory purchasing decision searching and evaluating information & 0.791 & 83.35 & & & \\
\hline & Ability to face the threats coming from competitors & 0.887 & 79.01 & & & \\
\hline & Ability to face the changes coming from external business environment. & 0.851 & 59.56 & & & \\
\hline \multirow[t]{4}{*}{4.} & Network Density & & & 0.892 & 0.735 & 0.820 \\
\hline & DENS social net & 0.872 & 77.26 & & & \\
\hline & DENS business net & 0.847 & 48.79 & & & \\
\hline & DENS supportive net & 0,855 & 53.19 & & & \\
\hline \multirow[t]{4}{*}{5.} & Network Size & & & 0.881 & 0.712 & 0.798 \\
\hline & NSIZE social net & 0.853 & 59.44 & & & \\
\hline & NSIZE business net & 0.871 & 80.40 & & & \\
\hline & NSIZE supportive net & 0.855 & 60.13 & & & \\
\hline \multirow[t]{3}{*}{6.} & Inter-personal Trust (Creditable) & & & 0.940 & 0.735 & 0.923 \\
\hline & I feel that buyers are honest & 0.884 & 67.45 & & & \\
\hline & I feel that suppliers are honest & 0.881 & 76.05 & & & \\
\hline
\end{tabular}




\begin{tabular}{|c|c|c|c|c|c|c|}
\hline \multicolumn{2}{|c|}{ Construct } & \multirow{2}{*}{$\begin{array}{l}\text { Loading } \\
0.896\end{array}$} & \multirow{2}{*}{$\begin{array}{l}t \text {-statistics } \\
107.53\end{array}$} & \multirow[t]{2}{*}{ CR } & \multirow[t]{2}{*}{ AVE } & \multirow[t]{2}{*}{$\alpha$} \\
\hline & I feel that buyers are trustworthy & & & & & \\
\hline & I feel that suppliers are trustworthy & 0.868 & 69.04 & & & \\
\hline & Buyers do not break promises & 0.944 & 165.61 & & & \\
\hline & Suppliers do not break promises & 0.942 & 173.42 & & & \\
\hline & Buyer are flexibility & 0.929 & 122.99 & & & \\
\hline & Suppliers are flexibility & 0.927 & 117.48 & & & \\
\hline & Buyers treat fairly for me & 0.937 & 153.37 & & & \\
\hline & Suppliers treat fairly for me & 0.930 & 117.89 & & & \\
\hline & I am sure that buyers would not knowingly do anything to hurt me & 0.930 & 130.70 & & & \\
\hline & I am sure that suppliers would not knowingly do anything to hurt me & 0.925 & 110.66 & & & \\
\hline \multirow[t]{7}{*}{7.} & Inter-personal Trust (Benevolence) & & & 0.941 & 0.842 & 0.906 \\
\hline & I feel that buyers cares about me giving higher attention for my request & 0.913 & 91.72 & & & \\
\hline & I feel that suppliers cares about me giving higher attention for my request & 0.917 & 103.14 & & & \\
\hline & I feel that buyers cares about me giving higher attention for my request. & 0.912 & 102.37 & & & \\
\hline & I feel that supplier cares about me giving higher attention for my request. & 0.915 & 99.11 & & & \\
\hline & I feel that buyer will sacrifice time, energy and resources to fulfil my request & 0.828 & 55.11 & & & \\
\hline & I feel that supplier will sacrifice time, energy and resources to fulfil my request & 0.825 & 53.97 & & & \\
\hline \multirow[t]{6}{*}{8.} & Norm of Information Exchange & & & 0.926 & 0.760 & 0.894 \\
\hline & Buyers provide useful information (unforeseen market trends and threats). & 0.719 & 23.02 & & & \\
\hline & Suppliers provide useful information (unforeseen market trends and threats). & 0.795 & 32.80 & & & \\
\hline & $\begin{array}{l}\text { Suppliers provide information which helps us to plan and organize my transaction activities in } \\
\text { advance (future market trends etc.). }\end{array}$ & 0.711 & 19.56 & & & \\
\hline & $\begin{array}{l}\text { Buyers support me providing confidential information that is important to my firm (new } \\
\text { techniques, reliability of exchange partners). }\end{array}$ & 0.712 & 30.41 & & & \\
\hline & $\begin{array}{l}\text { Suppliers support me providing confidential information that is important to my firm (new } \\
\text { techniques, reliability of exchange partners). }\end{array}$ & 0.705 & 30.38 & & & \\
\hline \multirow[t]{5}{*}{9.} & Norm of Flexibility & & & 0.941 & 0.888 & 0.874 \\
\hline & $\begin{array}{l}\text { Buyers are flexible to change the promises and agreements when my firm faces unexpected } \\
\text { situation (Cancel orders, delay the credit instalments). }\end{array}$ & 0.842 & 58.39 & & & \\
\hline & $\begin{array}{l}\text { Suppliers are flexible to change the promises and agreements when my firm faces unexpected } \\
\text { situation (Cancel orders, delay the credit instalments). }\end{array}$ & 0.891 & 81.97 & & & \\
\hline & $\begin{array}{l}\text { If I fail to perform according to the previous promises or agreement, buyers will not force me } \\
\text { (force to pay delayed credit instalments). }\end{array}$ & 0.875 & 60.25 & & & \\
\hline & $\begin{array}{l}\text { If I fail to perform according to the previous promises or agreement, suppliers will not force me } \\
\text { (force to pay delayed credit instalments). }\end{array}$ & 0.879 & 65.02 & & & \\
\hline \multirow[t]{7}{*}{10.} & Norm of Solidarity & & & 0.929 & 0.814 & 0.886 \\
\hline & $\begin{array}{l}\text { They are not behaving opportunistically and show their fairness in many activities (payments, } \\
\text { information and resources sharing) }\end{array}$ & 0.886 & 84.72 & & & \\
\hline & $\begin{array}{l}\text { They are not behaving opportunistically and show their fairness in many activities (payments, } \\
\text { information and resources sharing) }\end{array}$ & 0.878 & 73.21 & & & \\
\hline & $\begin{array}{l}\text { If I fail to perform according to the previous promises when I face difficult situation, buyers } \\
\text { discuss with me and find possible solution jointly. }\end{array}$ & 0.922 & 91.31 & & & \\
\hline & $\begin{array}{l}\text { If I fail to perform according to the previous promises when I face difficult situation, suppliers } \\
\text { discuss with me and find possible solution jointly. }\end{array}$ & 0.900 & 91.73 & & & \\
\hline & Buyers devote their time, resources and opportunities to continue the relationship with me. & 0.925 & 117.05 & & & \\
\hline & Suppliers devote their time, resources and opportunities to continue the relationship with me. & 0.934 & 141.30 & & & \\
\hline \multirow[t]{5}{*}{11.} & Norm of Role of Integrity & & & 0.886 & 0.795 & 0.743 \\
\hline & Buyers do not try to gain short term benefits which harm to the relationship between us & 0.849 & 63.73 & & & \\
\hline & Suppliers do not try to gain short term benefits which harm to the relationship between us & 0.849 & 56.84 & & & \\
\hline & $\begin{array}{l}\text { Buyers highly value the relationship and do not engage in cheating or any other dishonest } \\
\text { conduct }\end{array}$ & 0.857 & 66.28 & & & \\
\hline & $\begin{array}{l}\text { Suppliers highly value the relationship and do not engage in cheating or any other dishonest } \\
\text { conduct }\end{array}$ & 0.894 & 82.58 & & & \\
\hline \multirow[t]{5}{*}{12.} & Norm of Reciprocity & & & 0.858 & 0.751 & 0.669 \\
\hline & Buyers do not try to gain short term benefits which harm to the relationship between us & 0.892 & 118.06 & & & \\
\hline & Suppliers do not try to gain short term benefits which harm to the relationship between us & 0.851 & 50.44 & & & \\
\hline & Buyers ignore unexpected mistakes made by me & 0.892 & 87.92 & & & \\
\hline & Suppliers ignore unexpected mistakes made by me & 0.880 & 73.31 & & & \\
\hline \multirow[t]{4}{*}{13.} & Shared Vision & & & 0.869 & 0.769 & 0.702 \\
\hline & They share common ambitions that we all need to achieve success & 0.865 & 64.18 & & & \\
\hline & They have common understand to avoid distress of network members. & 0.865 & 63.68 & & & \\
\hline & $\begin{array}{l}\text { They have common understand to share new business opportunities (like new order to supply) } \\
\text { with me (To play a role as a sub-contractor, supplier, buyer, etc.). }\end{array}$ & 0.861 & 48.56 & & & \\
\hline
\end{tabular}

$(\mathrm{n}=373)$.

Source: Survey data, 2016. 
The second-order constructs were developed using latent variable scores of the first-order constructs. Indicator reliability of four latent variables at the second order level in the hierarchical model were evaluated. All path coefficients (standardised factor loadings) were well above the threshold value 0.7 (see table 2). The bootstrapping procedure was conducted to estimate the significance of each path coefficient by examining the t-statistics. All the t-statistics were significant at 0.05 significance level (see table 2). Hence, the results show the strong evidence for indicator reliability of the second order constructs as well. Table 2 displays that the
Cronbach's $\alpha$ was higher than the required value of 0.7 and composite reliability was higher than the recommended 0.7 value. With a higher level of the Cronbach's $\alpha$ and composite reliability, the second order constructs were developed in reliable manner. AVE for the each construct was higher than the required value 0.5 . The results confirm the convergent validity of the second order construct (see table 2). Discriminate validity of the second order constructs showed that none of the inter-construct correlation value was above the square-root of the AVE and satisfied the criterion of the discriminant validity of the second order constructs.

Table 2. Analysis of the Second Order Constructs.

\begin{tabular}{|c|c|c|c|c|c|c|}
\hline & Construct & Loading & t-statistics & CR & AVE & Cronbach's $\alpha$ \\
\hline \multirow[t]{4}{*}{1.} & Rational Ability (RA) & & & 0.944 & 0.850 & 0.912 \\
\hline & Access Information & 0.911 & 7.89 & & & \\
\hline & Assess Information & 0.934 & 7.92 & & & \\
\hline & Decision Making Ability & 0.919 & 7.91 & & & \\
\hline \multirow[t]{6}{*}{2.} & Norms & & & 0.949 & 0.799 & 0.933 \\
\hline & Flexibility & 0.933 & 125.91 & & & \\
\hline & Information Exchange & 0.882 & 78.56 & & & \\
\hline & Reciprocity & 0.815 & 33.50 & & & \\
\hline & Role of Integrity & 0.877 & 55.79 & & & \\
\hline & Solidarity & 0.936 & 148.11 & & & \\
\hline \multirow[t]{3}{*}{3.} & Inter-personal Trust & & & 0.969 & 0.942 & 0.937 \\
\hline & Benevolence Trust & 0.970 & 270.63 & & & \\
\hline & Creditable trust & 0.969 & 256.31 & & & \\
\hline
\end{tabular}

$(n=373)$. Source: Survey data, 2016.

The efficiency of the structural model were assessed using five step approach suggested. First, Multi-collinearity issues were assessed. The study calculates VIF and tolerance level with the support of linear regression option in SPSS (version 21.0). Considering the collinearity between independent constructs and dependent constructs in the structural model, results indicated that there are no multi-collinearity issues among variables. VIF values for all the path show minimal collinearity, ranging from 1.419 to 4.406 . These values are significantly less than the recommended threshold value of 5.00. The tolerance levels range from 0.285 to 0.705 exceeding 0.20 . These results provide a strong evidence for the absent of multi-collinearity issues between the independent constructs and the dependent constructs in the structural model.

Second, the study assessed the significance of the path coefficients using $\beta$ value and t-statistics. The table 3 shows that all the hypothetical relationships are statistically significant. Third, the explanatory power of dependent variable was substantial $\left(\mathrm{R}^{2}=0.737\right)$. Fourth, all the independent variables $\left(f^{2}\right.$ of the network size is 0.567 , network density is 0.795 , ties strength is 0.852 , relationship quality is 0.730 and shared vision is 0.943 ) represent a large effect size for predictive variables. Fifth, predictive relevance $\left(\mathrm{Q}^{2}\right)$ of rational ability is 0.624 which displays a substantial higher explanatory power.

As expected, the study found that information access through SSC has a positive impact on the improvement of rational ability of the OMSEs. Considering the influence of the information access through network size of the OMSE, the results show that information access through network size has an impact on the improvement of rational ability of the OMSEs by 20.8 percent $(\beta=0.208)$, the regression coefficient is positive significant $(t$-value $=4.44)$. Thus, hypothesis H1 is strongly proved by the survey results. The regression results shown in table 3 indicate that information access through network density of the OMSEs has an influence on the improvement of rational ability.

Table 3. Path Coefficients and Significance among Constructs.

\begin{tabular}{lllll}
\hline H & Relationship & $\boldsymbol{\beta}$ & $\boldsymbol{t}$-Statistics & Result \\
\hline H1 & Network Size -> RA & 0.208 & $4.44 * * *$ & Supported \\
H2 & Network Density -> RA & 0.133 & $4.43^{* * *}$ & Supported \\
H3 & Ties Strength -> RA & 0.158 & $5.49 * * *$ & Supported \\
H4 & Relationship Quality -> RA & 0.314 & $7.83 * * *$ & Supported \\
H5 & Shared Vision -> RA & 0.262 & $6.26 * * *$ & Supported \\
\hline
\end{tabular}

$* * * \mathrm{p}<0.01 .(\mathrm{n}=373)$.Source: Survey data, 2016.

The results strongly supported the hypothesis $\mathrm{H} 2$ on the basis of the significant positive regression coefficient $(\beta=$ 0.133 and $t$-value $=4.43$ ). A large number of studies [9], [16], [35], [38], [40] empirically confirmed that network structure plays an important role in sharing information which leads to improve rational ability (mitigate bounded rationality). The results of this study further strengthen the idea of Coleman [14] who explained that dense network exchanges information among members. Network structure has an ability to access information and get the support to evaluate information. Ting et al. [35] explained that network size helps to tap information in external environment 
successfully and reduce information asymmetry. Nooteboom [4] explained that increasing the ability to spread of personal networks (size), rationality could be improved. These ideas are further verified by the empirical results of the study.

Table 3 further illustrates that the information access through RSC has a positive influence on the improvement of the rational ability of the OMSEs. The strength of ties positively affects the improvement of the rational ability of the OMSEs $(\beta=0.158$ and $t$-value $=5.49)$ confirming the hypothetical relationship denoted by $\mathrm{H} 3$. Although the scholars have not paid their attention to study the rational ability, many scholars [7], [26], [38], [46] have studied the relationship between the strong ties and the information exchange. Uzzi [38] found that strong ties provide access to fine-grained information. Uzzi [38] further explained that the fine information enables the exchange partners bounded by the strong ties to reach 'economies of time'. Uzzi [38] argued that strong ties promote the transfer of complex knowledge which leads to improve rationality. The result of the study justify that OMSEs are rich in strength of ties, owners of SEs have an ability to access information, knowledge and obtain advice and opinion and thereby owners can improve their rational ability.

The regression results shown in the table 3 explain that the relationship between the information access through relational qualities and the rational ability of the OMSEs have a positive relationship supporting the hypothesis $\mathrm{H} 5$, on the basis of the significant positive path coefficient $(\beta=$ 0.314 and $t$-value $=7.93)$. Similar, the results have been given by many scholars in different studies. The interpersonal trust has an effect on the knowledge in exchanging accurate, secret and important information [60]. Inkpen and Tsang [39] found that the inter-personal trust and the relational norms have a positive impact on sharing information among network members. Anderson and Weitz [50] found that the norm of information exchange provides each other information which they normally do not disclose to the common exchange parties. Dyer and Chu [26] empirically observed that the information exchange between the exchange partners reduced the information asymmetry.

The CSC has a positive influence on the improvement of rational ability of the OMSEs. Table 3 shows that the CSC has a strong positive impact on the rational ability of the OMSEs $(\beta=0.262$ and $t$-value $=6.26)$ confirming the hypothetical relationship of H5. Chiu et al. (2006) [52] in their empirical study found that common understanding was positively related to the quality of information and the knowledge sharing and thereby exchange ideas and opinions which promote mutual understanding (rational ability). The results of this study show that the common understanding among members helps to access and assess information which facilitates to improve the rationality of OMSEs.

\section{Conclusion}

The study analysed the effect of information access through social capital of OMSEs on the improvement of rational ability. To achieve this aim, working hypotheses have been developed to test how information access through each dimension of SC affects the rational ability of OMSE in Sri Lanka. The results revealed that information access through all the dimensions of SC have significant positive impact on the improvement of rational ability of OMSEs. The study has made several contributions to the knowledge. First, the framework developed by synthesising all the dimensions of SC and rational ability into a new framework which contributed to extend the knowledge about the relative efficacy of theories into a different economic and social context. Second, this study makes important contributions to the literature providing empirical evidences related to how information access through SC affect the rational ability of OMSEs in Sri Lanka by testing hypotheses using empirical data. Third, the critical issue faced by SEs is the higher mortality rate which generally arise due to the limitations mostly reflected in TC. The study extends the application of the SCT with the BRT to understand an alternative solution for this critical issue. The empirical results provide sufficient evidences to understand the strength of social capital to govern economic activities rather than the market mechanism, conforming the complementary effect of SC in governing economic activities. Thus, the study provides an insight revealing that business firms can consume more benefits of the economies of scale suggested by the theory of production, by enlarging the capacity of SC to access information which help to improve rational ability of OMSEs and mitigate opportunism.

\subsection{Policy Implications}

The study proposes three recommendations for policy makers. First, OMSEs have ability to access and assess information through SC and information access through SC has a powerful effect on improving rational ability of OMSEs. Therefore, policy makers should develop mechanism to encourage OMSEs to build up more relationship with different categories of network. In this regard, the study recommends policymakers to provide necessary supports to develop relationship through web page, providing broad brand connections for SEs in order to develop more connections among network members both in locally and internationally.

Second, the study observed that the most of the OMSEs have developed close relationship with a few reliable buyers and suppliers (most of them are in surrounding areas or in the same region) for regular transactions. Therefore, most SEs limit themselves only the survival stage in their business. SEs do not have enough capacity to establish direct relationship with different exchange partners (particularly both local and foreign producers/ suppliers/ buyers) due to resources limitation. Therefore, the study strongly recommends that policy makers should develop mechanism to create relationship between SEs and new exchange partners both local and overseas (organizing network formation activities such as seminars, trade fairs etc., providing information about reliable or guaranteed exchange partners through a webpage of responsible agency). 
Third, policymakers can develop approaches to provide necessary supports to access information through social media. Government agencies, private sector and NGOs can maintain information services (through web page, providing broad brand connections for SEs) to access information and develop more connections among network members both in local and international markets.

\subsection{Research Direction}

Measuring SC dimensions and rationality were not easy because both variables are broad and multi-dimensional concepts. For the both concepts, there is no standard methodology to measure empirically (i.e. bounded rationality, SC). Developing systematic methodology to measure bounded rationality and SC in the context of developing counties need to be addressed in future researchers.

Finally, scholars have argued that building SC is an investment, but it takes time, money and effort. The costs of maintenance of SC vary according to various factors such as the nature of relationships, network size and density. Therefore, it is interesting to measure the opportunity costs of building and maintenance of SC and to evaluate its benefits. Since it is beyond the scope of this paper, the study leaves this question for future researchers.

\section{References}

[1] J. E. Hobbs. A transaction cost approach to supply chain management. Supply Chain Management, 1996, 1(2): 15-27.

[2] C. N. Pitelis and A. N. Pseiridis. Transaction costs versus resource value. Journal of Economic Studies, 1999, 26(3): 221-240.

[3] G. Spraakman. Transaction cost economics: a theory for internal audit. Managerial Auditing Journal, 1997, 12(7): 323330 .

[4] B. Nooteboom. Firm size effect on transaction cost, Small Business Economics, 1993, 5: 283-295.

[5] E. Carmel and B. Nicholson. Small firms and offshore software outsourcing: high transaction costs and their mitigation. Journal of Global Information Management, 2005, 13(3): 33-54.

[6] S. Bhagavatula, Weaving social networks performance of small rural firms in India as an outcome of entrepreneurs' social and human capital. PhD Dissertation, Visakhapatnam University, India. 2009.

[7] H. Lu. The role of guanxi in buyer-seller relationships in China, PhD thesis, Wageningen University, China. 2007.

[8] H. H. S. Priyanath and S. P. Premaratne. Effect of social capital on transaction cost: a case study of small enterprises in Sri Lanka, International Journal of Arts and Commerce, 2015, 4(4): 127-140.

[9] M. Granovetter. Economic action and social structure: the problem of embeddedness. American Journal of Sociology, 1985, 91(3): 481-510.
[10] S. P. Premaratne. Entrepreneurial Networks and Small Business Development: The Case of Sri Lanka, PhD Dissertation, Eindhoven University of Technology, Eindhoven, The Netherlands. 2002.

[11] P. S. Adler and S. W. Kwon. Social capital: prospects for a new concept. The Academy of Management Review, 2002, 27(1): 17-40.

[12] R. Bwalya, J. Mugisha and T. Hyuha. Transaction costs and smallholder household access to maize markets in Zambia. Journal of Development and Agricultural Economics, 2013, 8(9): 328-336.

[13] E. Priyanto, M. Mazkie and M. Khusaini. Effects of asymmetric information, transaction cost to corporate governance, and public organization performance. IOSR Journal of Business and Management, 2014, 15(6): 14-27.

[14] J. S. Coleman. Social capital in the creation of human capital. The American Journal of Sociology, 1988, 94(12): 95-120.

[15] R. D. Putnam. Making democracy work: Civic traditions in modern Italy. Princeton: Princeton University Press. 1995.

[16] R. S. Burt. The cognitive value of social capital. Administrative Science Quarterly, 1997, 42(2): 339-365.

[17] P. Moran. Structural vs. relational embeddedness: social capital and managerial Performance. Strategic Management Journal, 2005, 26(5): 1129-1151.

[18] J. Nahapiet and S. Ghoshal. Social capital, intellectual capital, and the organizational advantage. Academy of Management Review, 1998, 23(2): 242-266.

[19] H. Babaei, N. Ahmad and S. S. Gill. Bonding, bridging and linking social capital and empowerment among squatter settlements in Teheran, Iran. World Applied Sciences Journal, 2012, 17(1): 119-126.

[20] M. C. Bolino, W. H. Turnley and J. M. Bloodgood. Citizenship behavior and the creation of social capital in organizations. Academy of Management Review, 2002, 27(4): 505-522.

[21] F. Fukuyama. Trust: The Social Virtues and the Creation of Prosperity. New York: The Free Press, 1995.

[22] P. P. Chowdhury. Antecedents and consequences of trust and commitment in B2B relationship: are view of literature. International Marketing, 2012, 4(2): 49-63.

[23] J. H. Dyer and W. J. Chu. The role of trustworthiness in reducing transaction costs and improving performance: empirical evidence from the United States, Japan, and Korea. Organization Science, 2003, 14(1): 57-68.

[24] A. I. Rokkan, J. B. Heide and K. H. Wathne. Specific investments in marketing relationships: expropriation and bonding effects. Journal of Marketing, 2003, 40(2), 210-224.

[25] W. P. Wu and W. L. Choi. Transaction cost, social capital and firms' synergy creation in Chinese business networks: an integrative approach. Asia Pacific Journal of Management, 2005, 21(3), 325-343.

[26] W. S. Chow and L. S. Chan. Social network, social trust and shared goals in organizational knowledge sharing. Information \& Management, 2008, 45(7): 458-465. 
[27] W. Tsai and S. Ghoshal. Social capital and value creation: the role of intra firm networks. The Academy of Management Journal, 1998, 41(4): 464-476.

[28] I. Kitapci. Cognitive social capital as an interdisciplinary concept. International Journal of Economic Studies, 2016, 2(3): 13-23.

[29] N. Wang. Measuring transaction costs: an incomplete survey. Working Paper 2, The Ronald Cease Institute. (2003).

[30] R. H. Coase. The Nature of the Firm. Economica, 1937, 4: 386-405.

[31] O. E. Williamson. The economics of organization: transaction costs approach. American Journal of Social, 1981, 87(3): 548577.

[32] A. Zhang. Corruption as a determinant of transaction governance structure. Strategic Outsourcing: An International Journal, 2009, 2(1): 27-36.

[33] J. T. Macher and B. D. Richman. Transaction cost economics: an assessment of empirical research in the social sciences. Business and Politics, 2008, 10(1); 1-33.

[34] O. E. Williamson. The Economic Institutions of Capitalism: Firms, Markets and Relational contracting, New York: Free Press, 1985.

[35] S. H. Ting, C. N. Chen and D. E. Bartholomew. An integrated study of entrepreneurs' opportunism. Journal of Business \& Industrial Marketing, 2007, 22(5): 322-335.

[36] B. Wellman and K. Frank. Network capital in a multi-level world: Getting support from personal communities. In N. Lin, K. Cook, \& R. Burt (Eds.), Social capital: Theory and research Hawthorne: Aldine de Gruyter. 2001: 233-273.

[37] T. Bouzdine and M. B. Lorgnier. The role of social capital within business networks: Analysis of structural and relational arguments. Paper presented at the Fifth European Conference on Organizational Knowledge, Learning and Capabilities, Innsbruck, Austria. 2004.

[38] B. Uzzi. Social structure and competition in inter-firm networks: the paradox of embeddedness administrative. Science Quarterly, 1997, 42(3), 35-67.

[39] A. C. Inkpen and E. W. K. Tsang. Social capital network, and knowledge transfers. Academy of Management Review, 2005, 20(1): 146-165.

[40] W. E. Baker. Market networks and corporate behavior. American Journal of Sociology, 1990, 96(3): 589-625.

[41] N. H. Ahmad and P. S. Seet. Dissecting behaviours associated with business failure: A qualitative study of SME owners in Malaysia and Australia. Asian Social Science, 2009, 5(9): 98-104.

[42] Z. Li and F. Luo. Research on the relationship among social capital, organizational learning and knowledge transfer performance. Journal of Software, 2011, 3(9): 1763-1770.

[43] M. Granovetter. The strength of weak ties, American Journal of Sociology, 1973, 78(6), 1360-1380.

[44] B. Gerdoci, E. Skreli and D. Imami. Determinants of Sustainable Relationships in the Albanian Apple Production Sector. International Journal on Food System Dynamics, 2016, 7(1): 50-65.
[45] V. A. Gilsing and B. Nooteboom. Density and Strength of Ties in Innovation Networks: An Analysis of Multi-Media and Biotechnology (Center Discussion Paper; Vol. 2005-41). Tilburg: Organization. 2005.

[46] T. J. Rowley, B. Behrens and D. Krackhardt. Redundant government structures: an analysis of structural and relational embeddedness in the steel and semi-conductor industries. Strategic Management Journal, 2000, 21(6): 369-386.

[47] C. Steinfield, N. B. Ellison and C. Lampe. Social capital, selfesteem, and use of online social network sites: A longitudinal analysis. Journal of Applied Developmental Psychology, 2008, 29(2): 434-445.

[48] M. Khalique, A. H. M. Isa, J. A. N. Shaari and A. Ageel. Challenges faced by the small and medium enterprises (SMEs) in Malaysia: An intellectual capital perspective. International Journal of Current Research, 2011, 33(6): 398-401.

[49] J. B. Heide and G. John. Do Norms Matter in Marketing Relationships? The Journal of Marketing, 1992, 56(2): 32-44.

[50] E. Anderson and B. Weitz. The use of pledges to build and sustain commitment in distribution channels, Journal of Marketing Research, 1992, 29(1): 18-34.

[51] W. R. Doucette. The influence of relational norms and trust on customer satisfaction in inter firm exchange relationship. Journal of Consumer Satisfaction, Dissatisfaction and Complaining Behavior, 1996, 9(5): 95-103.

[52] C. M. Chiu, M. H. Hsu and E. T. G. Wang. Understanding knowledge sharing in virtual communities: an integration of social capital and social cognitive theories. Decision Support Systems, 2006, 42(3), 1872-1888.

[53] R. V. Krejcie and D. W. Morgan. Determining sample size research activities. Educational and Psychological Measurement, 1970, 30(2): 607-610.

[54] R. V. Patulny and G. H. L. Svendsen. Exploring the social capital grid: bonding, bridging, qualitative and quantitative. International Journal of Sociology and Social Policy, 2007, 27(2), 32-51.

[55] R. Silkoset. Negative and positive effects of social capital on co-located firms' withholding efforts. European Journal of Marketing, 2013, 47(2): 174-197.

[56] H. Lu, S. Feng, J. H. Trienekens and S. W. F. Omta. Network strength, transaction-specific investments, inter -personal trust, and relationship satisfaction in Chinese Agri-food SMEs. China Agricultural Economic Review, 2012, 4(3): 363-378.

[57] S. Ganesan. Determinants of long-term orientation in buyerseller relationships. Journal of Marketing, 1994, 58(2): 1-19.

[58] A. Zaheer, B. McEvily and V. Perrone. Does trust matter? Exploring the effects of Inter-organizational and inter-personal trust on performance. Organization Science, 1998, 9(2): 141-159.

[59] N. J. Miller, T. L. Besser and S. S. Weber. Networking as marketing strategy: a case study of small community businesses. Qualitative Market Research: An International Journal, 2010, 13(3): 253-270.

[60] W. Stam, S. Arzlanian and T. Elfring. Social capital of entrepreneurs and small firm performance: A meta-analysis of contextual and methodological moderators. Journal of Business Venturing, 2013, 21(3): 103-128. 